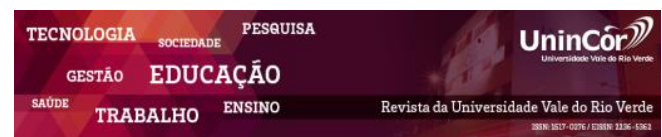

Revista da Universidade Vale do Rio Verde ISSN: 1517-0276 / EISSN: 2236-5362 v. $17 \mid$ n. 1 | Ano 2019

Igor Cavalcante Doi Universidade Estadual de Campinas igorcavalcantedoi@gmail.com

\section{QUESTÕES ANTROPOLÓGICAS EM PUREZA E PERIGO DE MARY DOUGLAS}

\section{RESUMO}

Este ensaio procura construir uma leitura da obra de Mary Douglas Pureza e perigo, com a intenção de colocá-la em diálogo com alguns temas presentes na literatura antropológica. Procurase evidenciar que uma tal formulação teórica, como a de Douglas, possui conexões com contribuições de outros teóricos da disciplina. Parte-se do suposto de que uma obra deve sempre ser compreendida na comunicação com essas questões, noções, conceitos e teorias predecessoras, matéria-prima de qualquer inovação - e, nesse sentido, a obra revive as questões sobre poluição, religião, magia, classificações e também o problema das diferenças entre as sociedades consideradas modernas e as "primitivas". Para tanto, estabelece conexões e recebe influências de autores como Robertson Smith, Durkheim, Mauss, Hubert e Lévy-Bruhl. Conclui-se que a obra está permeada por muitas ideias consagradas da Antropologia e que é ilustrativa do processo de constante diálogo com o campo.

Palavras-chave: Mary Douglas. Religião. Ritual. Magia. Primitivos.

\section{ANTHROPOLOGICAL ISSUES ON PURITY AND DANGER BY MARY DOUGLAS}

\begin{abstract}
This essay aims to explore the work Purity and danger, by Mary Douglas, intending to relate it with some themes featured in anthropological literature. We try to show that such a theoretical formulation, like Douglas', has connections with other theorists' contributions. We start from the assumption that a work must always be comprehended through the dialogue with those former questions, notions, concepts and theories - raw material for any innovation. It revives issues on pollution, religion, magic, classifications and also the issue of differences between societies considered modern and the "primitives". For this purpose, it establishes connections and receives influences from authors like Robertson Smith, Durkheim, Mauss, Hubert and Lévy-Bruhl. We conclude that the work is permeated by a lot of enshrined anthropological ideas and that it illustrates the process of constant dialogue with the field.
\end{abstract}

Keywords: Mary Douglas. Religion. Ritual. Magic. Primitives.

Recebido em: 13/08/2018 - Aprovado em: 19/03/2019 - Disponibilizado em: 15/07/2019 


\section{INTRODUÇÂO}

Apesar do relativo silêncio que se estabeleceu sobre os primeiros trabalhos etnográficos de Mary Douglas a respeito do Congo Belga (cf. TAMBASCIA, 2010; 2011), muitas das ideias presentes em Pureza e perigo foram influenciadas por sua pesquisa de campo, contribuindo para torná-la a sua obra mais conhecida. Todavia, não só de sua trajetória na etnografia brotam os problemas que ela pretende trabalhar, mas também, e principalmente, das questões que lhe foram legadas pela tradição antropológica. Em vista disso, este ensaio procura observar na obra de Douglas a reavaliação proposta pela autora de alguns dos temas que a precederam. Sendo fruto de um curso de teorias antropológicas, este texto não se pretende uma pesquisa esmiuçada sobre Pureza e perigo e tampouco uma história intelectual da autora trata-se aqui de podermos fornecer uma leitura, que é feita a partir de alguns dos referenciais estudados na disciplina. Mais do que resenhar, essa leitura busca uma reflexão a partir de outros aportes, a fim de ilustrar como os autores não teorizam isoladamente: não obstante as impressões de revolução ou de ruptura que as obras podem nos evocar, um autor sempre se insere numa história intelectual, ambiente fértil no qual as perguntas, as hipóteses e as respostas podem ser reavaliadas, reformuladas, enfim, renovadas para revelar o "novo". A intenção é a de que, em sua simplicidade, tal leitura possa causar um duplo efeito: um geral, que diz respeito a encorajar leituras contextualizadas de obras teóricas em qualquer área do conhecimento; e um específico, fornecendo um itinerário para aqueles que estão iniciando a leitura desse clássico da Antropologia da religião - mas também das “classificações" - que é Pureza e Perigo. É claro que um estudo completo e infinitamente profundo sobre a obra estaria fora das possibilidades deste ensaio. Trata-se, principalmente, de uma discussão elementar sobre teorias antropológicas que esperamos que contribua com os recémchegados a esses estudos.

\section{A QUESTÃO RELIGIOSA}

Os porcos são interditos porque são imundos e os porcos são interditos porque são sagrados. Segundo Douglas, esta é uma das ilustrações trazidas por James Frazer do Velho Testamento para exemplificar a admitida confusão entre a ideia de sacralidade e a ideia de sujeira nas sociedades primitivas. Estamos aqui diante de uma questão antiga para aqueles que se ocupam em entender as sociedades alienígenas à Europa: as diferenças entre a religião referência do europeu (o cristianismo) e as religiões com que o europeu se deparou desde que ampliou seus horizontes de navegação.

Tal contraste de crenças já era alvo de observações no século XVI, quando um aventureiro como Jean de Léry (1961) dedicou, em seu Viagem às terras do brasil, muitas páginas ao que considerou uma ausência de divindades e rituais religiosos, descrevendo as crenças dos "brasileiros" sempre em relação à crença cristã. Três séculos depois, o problema de se entender as religiões primitivas persistia, mas nesse momento os estudiosos europeus tinham que lidar com um clima crescente de contestação à religião e com a ascensão da biologia evolutiva, o 
que resultou na geração de um pensamento evolucionista da sociedade e da própria religião (STOCKING JR, 1991). Dentre tais pensadores, Douglas vai estabelecer seu diálogo com William Robertson Smith, um protestante que defendia a tese de que era o sacrifício o elemento mais relevante da religião antiga, assim como insistia no fato de que práticas religiosas estavam intimamente ligadas à estrutura social (EVANSPRITCHARD, c1981). Não obstante sua orientação teológica, o autor teria herdado de Tylor a proposição de que o homem moderno civilizado seria o resultado de um processo de evolução social.

Como a própria autora vai explicitar, Durkheim teria se aproximado de Robertson Smith ao escrever As formas elementares da vida religiosa, no sentido de que "O livro todo desenvolve a idéia germinal de que os deuses primitivos são parte e parcela da comunidade, suas formas expressando acuradamente os detalhes da sua estrutura, seus poderes punindo e recompensando em seu favor" (DOUGLAS, 2012, p.32). Essa dívida pode ser sentida inequivocamente também em Pureza e perigo, já que toda construção argumentativa do texto se apoia na constatação de que as representações religiosas estão intimamente relacionadas à vida social. Em outras palavras, isso é dizer que o questionamento sobre a poluição em Douglas só pôde ser formulado porque se assenta sobre essa questão mais ampla das correspondências entre sociedade e crença (e procurando afastar-se de explicações psicologizantes).

\subsection{RELIGIÃO ESPIRITUAL E RELIGIÃO} MATERIAL

Ao se propor a estudar religião e pureza, contudo, alguns problemas se impõem quando a autora procura explorar os autores clássicos. O primeiro deles diz respeito à natureza da religião primitiva, considerada materialista, em oposição a uma religião moderna espiritual.

Vimos acima, de passagem, que Frazer considerava que a religião primitiva tinha como marca particular $o$ fato de não distinguir a santidade e a sujeira. Para além disso, a sujeira poderia ser também fonte de poderes profanadores, e assim a religião primitiva estaria, nesses estágios, também confundida com a higiene. Daí a convicção de que as religiões "ultrapassadas" teriam relação direta com questões materiais, de tal modo que o contato com as impurezas físicas seria fonte de poder e teria possibilidade de agir no plano imaterial. As religiões "avançadas", por outro lado, teriam evoluído para um desligamento completo da influência material, sendo o mundo espiritual influenciado apenas por questões de ordem intangível e nunca pela sujeira física. A evolução religiosa, nesse sentido, expressaria uma evolução do comportamento social, levando as sociedades de um ponto de materialismo e moral inferior a um status de espiritualidade e moral elevada.

\subsection{RELIGIÃO E MAGIA}

O segundo problema, seguindo a leitura que Douglas faz de Robertson Smith, se dá na costumeira divisão entre religião e magia. Se a evolução religiosa expressava um desenvolvimento moral, também era verdade que toda religião, mesmo as primitivas, traziam de 
alguma maneira sua correlação com os valores e as estruturas sociais. Por outro lado, se tradicionalmente a religião foi tida de tal modo, a magia era, em contraste, algo menos relevante, que importava apenas por sua eficácia. Era, assim, tratada como uma ferramenta de interferência direta sobre a natureza ou sobre os homens.

Durkheim (1996) seguiu esse pensamento, conduzindo-o a uma distinção entre sagrado e profano: a religião, na esfera do sagrado, foi por ele apreciada como prática ritual e representação coletiva do cosmo, intimamente relacionada à organização social, tendo inclusive um papel imprescindível para a elaboração das categorias do entendimento humano (um olhar sociológico sobre as categorias kantianas). Religião está aqui no mesmo compasso da organização social, das classificações e da elaboração de categorias.

Já a magia foi estudada por seus discípulos Marcel Mauss e Henry Hubert (2003). Considerada no universo do profano, a magia é pensada justamente como algo furtivo, que, em vez de pública e ostentatória como a religião, aparece sempre escondida, na maioria das vezes privada. O esforço em delinear as características distintivas dos ritos mágicos com base nas "condições nas quais eles se produzem e que marcam o lugar que ocupam no conjunto dos hábitos sociais" (id. ibid., p.61) esbarra em uma infinidade de exceções complicadas, já que a magia é privada, mas pode acontecer em público; é considerada excepcional, mas em alguns casos é regular; é profana, mas pode dialogar com as divindades; é maléfica, mas a religião também o pode ser. Mas o mais significativo é o fato de a magia ser considerada "mecânica". Ela pende mais para a técnica, para as artes, embora em certo ponto seja também considerada, assim como em Frazer (1982), como uma ciência primitiva. Mas só o é porque seu interesse reside na concretude, na natureza e seu funcionamento, ao invés da espiritualidade e metafísica. Nesse sentido, ela não conhece os mitos, como a religião; ela é "pouco poética, ela não quis fazer a história de seus demônios" (id. Ibid., p.121); e, se ela se relaciona com o divino, é apenas porque soube se aproveitar do prestígio da religião.

Essas ideias - (2.1) de que a dimensão ética é pouco presente na religião primitiva materialista e (2.2) de que os rituais podem ser divididos em sagrados (religiosos) e profanos (mágicos) - são elencadas para que a autora possa delas se afastar. Essas são divisões que, para Douglas, não ajudam a pensar o mundo simbólico primitivo. Em lugar de fragmentá-lo, deveríamos apenas "tentar comparar as visões dos povos sobre o destino do homem e seu lugar no universo" (DOUGLAS, 2012, p.42). O que ela faz é abalar uma tradição de estudos religiosos, sem o que ela pensa não ser possível avaliar o problema da poluição de maneira adequada. Mas não se trata de uma mera negação dos mestres do passado e sim de uma necessidade de acompanhálos para dar às suas preocupações antigas uma direção mais promissora. É inegável a importância de Durkheim e Robertson Smith, no sentido em que Pureza e perigo pensa justamente essa indissociabilidade de crenças, ritos e ordem social. Sua contribuição está precisamente no fato de retirar as divisões entre sagrado e profano, 
entre magia e religião, e dar atenção irrestrita aos rituais, que vêm a tornar-se o centro das suas análises, junto com aquilo que eles simbolizam.

O ritual será então pensado em termos de um modificador de experiências - um incesto, por exemplo, pode ser anulado através de um ritual; a morte ritual pode fazer o indivíduo escapar da morte normal, que em alguns casos pode ser devastadora; e, num sentido mais secular, os dias da semana ritualizam nossa experiência com o tempo, sem o que não o experienciaríamos do mesmo modo. Rituais podem ser religiosos ou seculares, presumir algum ou nenhum retorno material, evocar ou não entidades espirituais... não são essas divisões que estão em jogo. A questão colocada é sobre a sua possibilidade de alterar a experiência mundana.

\section{CLASSIFICAÇÕES, ORDEM E DESORDEM}

Para além do que diz respeito à religião, magia e ritual, muito do olhar sobre as impurezas é um reavivamento do problema durkheimiano das classificações, efetuando uma atualização que o leva a novos horizontes. Ora, porque, se Durkheim e Mauss (1999) estavam interessados em como a sociedade elabora classes de coisas que vão organizar sua experiência no mundo, Douglas vai à busca das classificações para atingir o inclassificado.

Durkheim e Mauss (1999) contestam a ideia da existência de uma lógica classificatória inerente, seja à natureza, seja à humanidade. Para eles, as classificações são formuladas segundo uma organização social. Como observam, avaliando grupos totêmicos, toda a natureza, para essas sociedades, está organizada segundo sua própria divisão totêmica interna. Disso se conclui que as classes de coisas não brotam do mundo são gestadas pela sociedade e impostas sobre a natureza que a rodeia.

Mas o que é preciso para que Douglas seja capaz de compreender a impureza é forçar a tese das classificações ao limite e encontrar o interstício das classes, onde se pode observar elementos que ou não pertencem a nenhuma classe definida ou são ambíguos, tentando pertencer desconfortavelmente a duas classes distintas. Essa proposta implica a observação de coisas e sujeitos que parecem abalar as classes estabelecidas - e é precisamente nessas frestas que se situam as poluições. "Como se sabe, a sujeira é, essencialmente, desordem" (DOUGLAS, 2012, p.12). Desse modo, há poderes que espreitam no inclassificado, no amorfo, no que assume posições ambíguas na estrutura social e em tudo que ameaça cruzar fronteiras.

Sobre as fronteiras, evoca Van Gennep (2011), quem observa que as formas de vida em sociedade estão preenchidas de limites que são constantemente transpostos através dos ritos de passagem. E é justamente num estado de transição, quando o indivíduo se situa na margem, sem pertencer definidamente a uma classe verdadeiramente própria, que Douglas vai enfatizar a presença do poder e a eminência do perigo, o que justifica a necessidade do ritual, pois "O perigo é controlado por um ritual $[. .$.$] .$ Não somente a transição em si é perigosa, mas também os rituais de segregação constituem a fase mais perigosa dos ritos" (DOUGLAS, 2012, p.120). 
De outro modo, os poderes poluitivos também se expressam em indivíduos de posição social ambígua. "As mulheres Kashin estão no meio da articulação de dois grupos de poder, a família do irmão e a do marido. Essa posição 'intersticial' é o que a dota de poderes incontroláveis" (DOUGLAS, 2012, p.126, itálico meu). Isto se dá dessa maneira porque a mulher está numa posição de nenhuma autoridade, mas seu desagrado constitui uma ameaça para os grupos de autoridade que ela articula, de tal modo que uma crença em poluição pode mantê-la sob controle. Para isso, atribui-se ao seu descontentamento riscos poluitivos.

A poluição ainda pode brotar de situações em que as regras morais estão presentes de maneira afrouxada ou em conflito com outras regras, o que torna essas situações incertas. Em condições de moral inequívocas, uma atitude inadequada pode ser severamente punida e o assunto imediatamente resolvido, mas, se há algum problema, alguma confusão, qualquer coisa que impeça que as regras sejam firmemente aplicadas, surgem os perigos da poluição. Entre os Nueres, por exemplo, o incesto é evidentemente proibido, mas há situações em que não se tem certeza de se o casamento é ou não incestuoso, de forma que o mais apropriado seria executar um ritual de anulação do incesto. Esta é uma situação moral indefinida, em que a crença na poluição permite que a experiência seja reformulada pelo ritual. Há também situações morais conflituosas, como quando duas regras se sobrepõem, impedindo que sanções físicas sejam aplicadas e a situação moral resolvida. Por exemplo: a mulher que deve ser submissa ao marido, mas cuja estrutura social impede que ele sancione a sua insubmissão de maneira violenta, é geralmente fonte de perigo.

Em outros exemplos como esse, as questões morais podem ser resolvidas pela poluição de algumas maneiras: (1) elas podem ser reduzidas a uma questão material e resolvidas com rituais de purificação, de fato demonstrando uma frouxidão da regra moral; (2) o perigo da poluição pode reforçar o fervor moral contra o autor do delito, uma vez que o alvo dos males da poluição pode vir a ser uma pessoa inocente (e rituais precisos podem determinar o causador do malefício); (3) o medo da poluição pode regular a ação das pessoas, já que o alvo do perigo pode ser o próprio autor do ato reprovável. De qualquer modo, a poluição fornece uma alternativa para questões morais que não podem ser resolvidas de forma direta.

Apesar de, à primeira vista, parecer que Douglas está falando de muitas coisas - tabus alimentares, rituais de passagem, estrutura social, parentesco, moral -, em verdade há uma questão central que é a ordem das coisas. Seja no modo como classificamos a natureza, como estruturamos a sociedade, como cruzamos as fronteiras simbólicas da vida, ou como concebemos o certo e o errado, o perigo espreita no território indefinido, pois o homem tem sempre que se deparar com aquilo que as suas formulações, sempre limitadas, não foram capazes de classificar e ordenar, de colocar em relação de uma maneira funcional e compreensível. Com isso, sua visão de poluição contribui para mostrar que muito daquilo que era considerado sob o rótulo de magia na verdade 
possui relações importantes com questões morais e também está profundamente relacionado com a ordem social, de modo que a autora pode sustentar ainda melhor, depois disso, a crítica à distinção entre magia e religião que faz no início do seu texto.

\section{O SUJO E O SAGRADO}

No que diz respeito à sua questão inicial, sobre a materialidade da religião primitiva, que era acusada de confundir a sacralidade e a sujeira, fica evidente que as coisas não se dão exatamente nesses termos. O que acontece realmente é que aquilo que vive às margens, os estados anômalos ou ambíguos, são sempre fontes de poder. E esse poder é perigoso e requer cuidados rituais, mas também pode ser usado positivamente pelos ritos. Daí a aparente "santidade" da sujeira. Assim, o que os antigos antropólogos perceberam como uma confusão entre religião e sujeira, é, na verdade, para Douglas, uma busca pelo poder justamente onde ele jaz: no interstício da estrutura das ideias. Ali está o perigo porque ali está o poder. E enquanto, na maior parte do tempo, os primitivos usam de seus rituais para evitar esse poder perigoso que os assola, é lá também que podem buscar o poder necessário para transformar sua experiência, porque também é verdade que, apesar de trazer conforto, "A pureza é inimiga da mudança” (p.196).

\section{NÓS E ELES}

Há ainda uma outra leitura que pode ser feita de Pureza e perigo, que diz respeito à discussão das diferenças entre primitivos e civilizados. A apreciação que Fardon (2004) faz da obra é justamente no sentido de observar como, ao longo do texto, Douglas traça uma discussão a respeito das diferenças entre "nós" e "eles".

A questão da diferença e da semelhança que os povos que se consideram modernos procuram em relação àqueles que consideram selvagens, bárbaros ou primitivos está colocada desde que as populações de tradição europeia entraram em contato com o vasto mundo. Segundo Laplantine (2007), esse problema teria sido formulado, em princípio, em termos de humanidade e não-humanidade. Era preciso determinar em primeiro lugar se aquelas pessoas, tão diferentes em aparência e costume, eram de fato humanas. Esse problema equivalia ao de saber se os selvagens eram ou não dotados de alma.

Com um misto de fascinação e repulsa, a questão do "nós" e "eles" motivou incursões filosóficas durante o Iluminismo e teve uma reviravolta na segunda metade do século XIX. Em muito contrariando teses poligenistas segundo as quais diversas origens para a espécie humana justificariam a existência de tamanhas diferenças - e pondo em cheque um certo degeneracionismo, para o qual a alma selvagem não teria salvação, uma emergente antropologia evolucionista colocou a humanidade dentro de uma só categoria em que cada povo variaria segundo graus diferentes de desenvolvimento. Apesar da inferioridade imputada aos povos selvagens, agora eles estavam irremediavelmente dentro da espécie humana e no curso de sua história geral, com um desenvolvimento possível, 
embora "atrasados" no caminho. Eram, finalmente, primitivos.

A virada do século vai transformar essa perspectiva. Boas (2004) criticou a falta de suporte empírico para respaldar as teorias evolucionistas e pontuou uma diferenciação das sociedades pela complexidade: para ele, as condições materiais de subsistência garantiam a possibilidade de complexificação da cultura (BOAS, 2010).

Durkheim colocou a questão em termos parecidos, de maneira que buscava fazer uma sociologia a partir das sociedades "simples". Aqui, se a distância entre primitivos e civilizados se dá em termos de complexidade, a proximidade está estabelecida na ideia de que é possível compreender questões profundas da vida em sociedade a partir do estudo do mais simples. Esse estudo generalista sugere que algo de elementar está presente lá e cá, em "nós" e "neles", algo que organiza as instituições e a vida em sociedade. As categorias, as classes, a ordem social, essas coisas são reguladas por forças sociais de formas provavelmente não idênticas, mas análogas e generalizáveis (DURKHEIM, 2006).

Foi Lévy-Bruhl (2008) quem concentrouse na questão das mentalidades. O pensamento civilizado seria caracterizado pela lógica e pela cientificidade, enquanto o pensamento primitivo seria pré-lógico e místico. Como salientou EvansPritchard (1978), isso não significava dizer que o primitivo não raciocina, mas que não se preocupa em evitar a contradição; isso porque que as mentalidades estariam rendidas às representações coletivas de que o indivíduo partilha, de modo que o alerta importante de Lévy-Bruhl era o de que, para entender o pensamento primitivo, é preciso concebê-lo em seu próprio modo de pensar.

A leitura feita de Pureza e perigo por Fardon (2004) aponta para a relevância desse problema para Douglas, que também se vê na necessidade de caracterizar o primitivo em contraste com o moderno, já que seus últimos capítulos versam justamente sobre os modos primitivos de lidar com a poluição. Ela discute uma divisão que considera equivocada e a desmonta, para então reestabelecer a divisão em outra região de ideias, sobre a qual vai trabalhar da metade do livro em diante.

Fardon (2004) vê nos primeiros capítulos uma correção a uma divisão equivocada entre civilizados e primitivos segundo a qual, como expus acima, se pretendia ver uns dotados de crenças materialistas e os outros abraçados a crenças totalmente espiritualizadas. As crenças em poluição tampouco estariam ausentes nas sociedades consideradas avançadas, pois todo ser humano necessita de um esquema de ideias, uma ordenação dada em termos de categorias e conceitos que lhe permitiria compreender o mundo sensível, donde surgiriam margens nebulosas, perigosas e poluitivas. Desse fardo não escapam os primitivos e não escapamos nós. E os modos de lidar com o problema não devem diferir tanto entre um e outro.

No capítulo quinto, contudo, há um reposicionamento da diferença. De uma maneira que lembra a distinção durkheimiana de solidariedades mecânica e orgânica (DURKHEIM, 2006), Douglas determina que há sociedades diferenciadas (modernas) e 
indiferenciadas (primitivas). Para ela, a diferenciação das instituições corresponderia a uma diferenciação das ideias; contudo, não se pode entender diferenciação de ideias como mera complexificação, já que há muitas sociedades indiferenciadas com cosmologias altamente complexas. Diferenciação, aqui, tem o sentido de uma descentralização do homem na explicação do cosmo.

A perspectiva é próxima a Lévy-Bruhl no sentido que estipula uma diferença da ordem das mentalidades, mas se distancia na medida em que o binômio do pensamento lógico/pré-lógico é substituído pelo dos pensamentos pessoalsubjetivo/impessoal-objetivo. O que caracteriza o mundo primitivo é que nele o cosmo age em função do homem. Tudo o que acontece, toda fortuna ou infortúnio cósmico é indissociável da vida humana, tudo está relacionado às observações que os indivíduos fazem das regras, das prescrições, dos rituais. O cosmo responde aos humanos, além de possuir características de pessoa, como juízo e sentimentos. Ademais, pode haver no universo "extensões do eu", de tal forma que um sentimento do indivíduo pode incidir sobre ele vindo "de fora". Inversamente, os povos ditos modernos seriam "copernicanos", capazes de compreender uma natureza impessoal.

Mas, se isso se aproxima de uma diferença de mentalidades, não se dá por uma falha de pensamento, ou por uma incompetência em avaliar o funcionamento do universo, porque as ideias que permeiam as sociedades primitivas não são fruto de elucubrações filosóficas; não é como se essas ideias pretendessem ser sistematicamente formuladas, mas lhe faltassem as ferramentas mentais ou as representações coletivas necessárias. Essas formulações conceituais, para Douglas, surgem apenas como um complemento das respostas práticas às necessidades práticas cotidianas: os ritos são praticados antes de serem fruto de investigação metafísica. Deslocando o problema das crenças para as práticas, Douglas se afasta de LévyBruhl, pois percebe que não existe tal diferença entre pensamento contraditório e nãocontraditório - na vida cotidiana, os seres humanos de qualquer sociedade dificilmente são filósofos que buscam explicações filosóficas profundas e coesas; os atos surgem de necessidades práticas do cotidiano social e só superficialmente vão se revestir de crenças, pois o mais importante do ponto de vista da maioria das pessoas em qualquer sociedade não são as teses metafísicas, mas os usos práticos de seus rituais.

Estabelecendo uma diferenciação no modo como primitivos e modernos pensam o mundo, colocando os primeiros como dotados de uma visão antropocêntrica do cosmo e os segundos como possuidores de uma visão objetiva de sua relação com a natureza, Douglas revive a discussão, considerada pertinente, entre dois tipos de sociedade. Mais uma vez, ela está a reorganizar debates antigos e tradicionais na antropologia.

\section{CONSIDERAÇÕES FINAIS}

A essa altura, já podemos constatar o quanto todo um corpo de discussões antropológicas pesa sobre Pureza e perigo. Podemos ver, como lembramos no início, a máxima de que um autor é movido pelas grandes 
questões de sua disciplina, pelas noções e conceitos elaborados, pelas teorias, pelos dados empíricos disponíveis. Nessa obra, Douglas trata do tema da poluição, mas trata também de muitos outros temas, sejam a religião, a magia, as classificações, a estrutura social, etc. E, partindo pelo rastro de seus antecessores, toma novas direções. Sua noção de poluição é encontrada no interstício das classificações que Durkheim se esforçou por mostrar como originárias da sociedade; também nas margens e suas transposições, com apoio de Van Gennep; nas brechas das estruturas; nas confusões morais. Ela reavalia os legados deixados por Robertson Smith sobre religião primitiva, materialidade e sujeira e a diferenciação de religião e magia, que teria passado por Frazer e Durkheim e alimentado por trabalhos como de Mauss e Hubert. E investe na concepção de Robertson Smith e Durkheim de que as crenças estão profundamente conectadas à organização social.

A obra ainda trabalha a diferença entre selvagens e primitivos, estabelecendo novos critérios de diferenciação. Primeiramente, recusa a distinção em termos de materialidade e espiritualidade religiosas, para depois estabelecer o contraste em termos da pessoalidade e impessoalidade do universo.

Tanto no trato com a religião e com o ritual como na sua exploração das diferenças entre "nós" e "eles", Douglas está lidando não apenas com autores específicos, mas com questões amplas da Antropologia, que constantemente se renovam. Seu trabalho, na maior parte, é uma contribuição à renovação desses grandes problemas.
No fim desta breve investigação, pudemos observar um pouco, então, aquilo a que eu me propus no início. De um lado, apreciamos a obra de Douglas colocada num cenário mais amplo; de outro, pudemos evidenciar como importam as questões, as noções, as teorias clássicas para a construção de um trabalho teórico. É na trilha desses clássicos “incontornáveis" (cf. SIGAUD, 2013), nós o vimos, que se colocou em sua época um trabalho inovador como Pureza e perigo.

\section{REFERÊNCIAS}

BOAS, F. A mente do ser humano primitivo e o progresso da cultura. In: . A mente do ser humano primitivo. Ptrópolis: Vozes, p. 137-54, 2010 .

- As limitações do método comparativo da antropologia. In: . Antropologia cultural. Rio de Janeiro: Zahar, p.25-40, 2004.

DE LÉRY, J. Viagem à Terra do Brasil. [s.1.]: Biblioteca do exército, 1961.

DOUGLAS, M. Pureza e perigo. São Paulo: Perspectiva, 2012.

DURKHEIM, E. As formas elementares da vida religiosa. São Paulo: Martins Fontes, 1996.

. Sociologia. São Paulo: Ática, 2006.

DURKHEIM, E.; MAUSS, M. Algumas formas primitivas de classificação. In: MAUSS, M. Ensaios de sociologia. São Paulo: Perspectiva, p.399-456, 1999.

EVANS-PRITCHARD, E. E. Antropologia social da religião. Rio de Janeiro: Campus, p. 111-38, 1978.

. História do pensamento antropológico.

Lisboa: Edições 70, c1981.

FARDON, R. Pureza e perigo revisitado. In:

Mary Douglas: uma biografia intelectual. Rio de Janeiro: UFRJ, 2004.

FRAZER, J. G. A magia simpática. In: $\mathbf{O}$ ramo de ouro. Rio de Janeiro: Guanabara Koogan, p.34-46, 1982.

LAPLANTINE, F. Aprender antropologia. São Paulo: Brasiliense, 2007.

LÉVY-BRUHL, L. A mentalidade primitiva. São Paulo: Paulus, 2008. 
MAUSS, M.; HUBERT, H. Esboço de uma teoria geral da magia. In: MAUSS, M. Sociologia e antropologia. São Paulo: Cosac Naify, p.47-181, 2003.

TAMBASCIA, C. Recontando Mary Douglas: metodologias de pesquisa para análise de uma trajetória intelectual. Espaço acadêmico, v.9, n.106, 2010 .

. Maginalidade relativa do africanismo de Mary Douglas: narrativas de uma análise do campo acadêmico britânico. Idéias, v. 2, n. 2, 2011.

SIGAUD, L. O mundo desmagicizado. Mana, v.19, n.3, p. 581-590, 2013.

STOCKING JR, G. W. Victorian anthropology. New York: The Free Press, 1991.

VAN GENNEP, A. Os ritos de passagem. Petrópolis: Vozes, 2011.

\section{Igor Cavalcante Doi}

Mestrando pela Unicamp na área de Educação Física e Sociedade, com ênfase em História Cultural 